\title{
Collagen Matrices as an Improved Model for In Vitro Study of Live Cells Using Raman Microspectroscopy
}

\author{
Franck Bonnier \\ Technological University Dublin, Franck.Bonnier@tudublin.ie \\ Peter Knief \\ Technological University Dublin, peter.knief@tudublin.ie \\ Aidan Meade \\ Technological University Dublin, aidan.meade@tudublin.ie
}

See next page for additional authors

Follow this and additional works at: https://arrow.tudublin.ie/radcon

Part of the Biochemistry, Biophysics, and Structural Biology Commons

\section{Recommended Citation}

Bonnier, F., Knief, P. \& Meade, A.D. (2011). Collagen Matrices As An Improved Model For In Vitro Study of Live Cells Using Raman Microspectroscopy. Clinical and Biomedical Spectroscopy and Imaging II, Munich, 24th May. doi:10.1117/12.889872

This Conference Paper is brought to you for free and open access by the Radiation and Environmental Science Centre at ARROW@TU Dublin. It has been accepted for inclusion in Conference papers by an authorized administrator of ARROW@TU Dublin. For more information, please contact arrow.admin@tudublin.ie, aisling.coyne@tudublin.ie,gerard.connolly@tudublin.ie. Funder: National Biophotonics and Imaging Platform (NBIP) Ireland funded under the Higher Education Authority PRTLI (Programme for Research in Third Level Institutions) Cycle 4, co-funded by the Irish Government and the European Union.

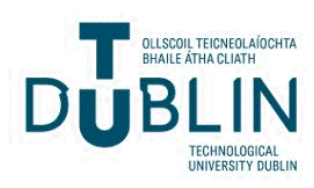




\section{Authors}

Franck Bonnier, Peter Knief, Aidan Meade, Jennifer Dorney, Kunal Bhattacharya, Fiona Lyng, and Hugh Byrne 


\title{
Collagen matrices as an improved model for in vitro study of live cells using Raman microspectroscopy
}

F. Bonnier, P. Knief, A. D. Meade, J. Dorney, K. Bhattacharya, F. M. Lyng and H. J. Byrne

Focas Research Institute, Dublin Institute of Technology (DIT), Camden Row, Dublin, 8, Ireland.

Invited Paper: Clinical and Biomedical Spectroscopy and Imaging II, edited by Nirmala Ramanujam, Jürgen Popp, Proc. of SPIE-OSA Biomedical Optics, SPIE Vol. 8087, 80870F • (c) 2011 SPIE-OSA · CCC code: 1605-7422/11/\$18 - doi: 10.1117/12.889872

\begin{abstract}
:
Due to its high lateral resolution, Raman microspectrsocopy is rapidly becoming an accepted technique for the subcellular imaging of single cells. Although the potential of the technique has frequently been demonstrated, many improvements have still to be realised to enhance the relevancy of the data collected. Although often employed, chemical fixation of cells can cause modifications to the molecular composition and therefore influence the observations made. However, the weak contribution of water to Raman spectra offers the potential to study live cells cultured in vitro using an immersion lens, giving the possibility to record highly specific spectra from cells in their original state. Unfortunately, in common 2-D culture models, the contribution of the substrates to the spectra recorded requires significant data pre-processing causing difficulties in developing automated methods for the correction of the spectra. Moreover, the 2-D in vitro cell model is not ideal and dissimilarities between different optical substrates within in vitro cell cultures results in morphological and functional changes to the cells. The interaction between the cells and their microenvironment is crucial to their behavior but also their response to different external agents such as radiation or anticancer drugs. In order to create an experimental model closer to the real conditions encountered by the cell in vivo, 3-D collagen gels have been evaluated as a substrate for the spectroscopic study of live cells. It is demonstrated that neither the medium used for cell culture nor the collagen gels themselves contribute to the spectra collected. Thus the background contributions are reduced to that of the water. Spectral measurements can be made in full cell culture medium, allowing prolonged measurement times. Optimizations made in the use of collagen gels for live cells analysis by Raman spectroscopy are encouraging and studying live cells within a collagenous microenvironment seems perfectly accessible.
\end{abstract}

Key words: Raman spectroscopy, live cells, collagen gels, culture medium 


\section{INTRODUCTION}

Raman spectroscopy has become a widely used technique for the analysis of biological materials over the last decade. The specificity of the information gleaned means it can provide crucial information about the molecular composition of the samples under investigation. Although many applications consist of mapping of tissue sections for the detection of pathological areas and the identification of specific markers usable for diagnostic purposes, the main advantage of the technique resides in its high spatial resolution. The potential of the technique to record spectra at the subcellular level has been demonstrated many times ${ }^{[1,2]}$. Using a high magnification objective such as $x 60$ or $\mathrm{x} 100$, the lateral resolution attainable is of the order of $\leq 1 \mu \mathrm{m}$, allowing the collection of specific spectral signatures from the different cellular compartments such as nucleoli, nucleus and cytoplasm ${ }^{[3,4]}$. Although the technique is usually described as non invasive and non destructive, the high intensity of the lasers employed can affect sensitive samples such as single cells. Therefore, the choice of the wavelength used is critical and in 1991 Puppels and al. highlighted that source wavelengths of $>660 \mathrm{~nm}$ are preferred to avoid any photodegradation of the cells under investigation ${ }^{[5]}$. Moreover, water has an extremely weak scattering efficiency, offering the possibility to work on live cells ${ }^{[6]}$. The different fixation methods commonly used can have an impact on the molecular composition and therefore on the information collected from the cells ${ }^{[7,8]}$ and in recent years the study of live cells has became the new target for applications of Raman spectroscopy. Using an immersion lens, live cells can be studied in saline solution giving a better representation of the cellular molecular composition and organization, resulting in improved relevancy of the results gleaned. Although Raman spectroscopy has a clear potential for the study of single cells, the technique suffers from some limitations that need to be considered when designing experiments. The presence of a strong spectral background remains the main problem for the preprocessing of the data. Although in the case of tissue analysis the background is usually ascribed to intense fluorescence ${ }^{[9,10]}$ or aberrant scattering due to the morphology of the samples ${ }^{[11]}$, it appears that when working on cells the main contribution to the background derives from the substrates used to grow the cells. Usually, cells are grown on polystyrene Petri-dishes but the Raman signal of the polymer itself is complex in the fingerprint region and contains many peaks that overlap with the cellular features (figure 1A). Because the cells are thin compared to the focal depth, even in a confocal mode, transparent substrates with low Raman signal are desirable. Glass has a broad Raman signature overlapping with the region of interest of the cellular spectra (figure 1B) and quartz is often preferred. However, although its contribution to the Raman spectrum is reduced compared to other substrates, it is still not ideal and standardization of background removal during the pre-processing stage remains difficult (figure 1C) ${ }^{[12]}$. 

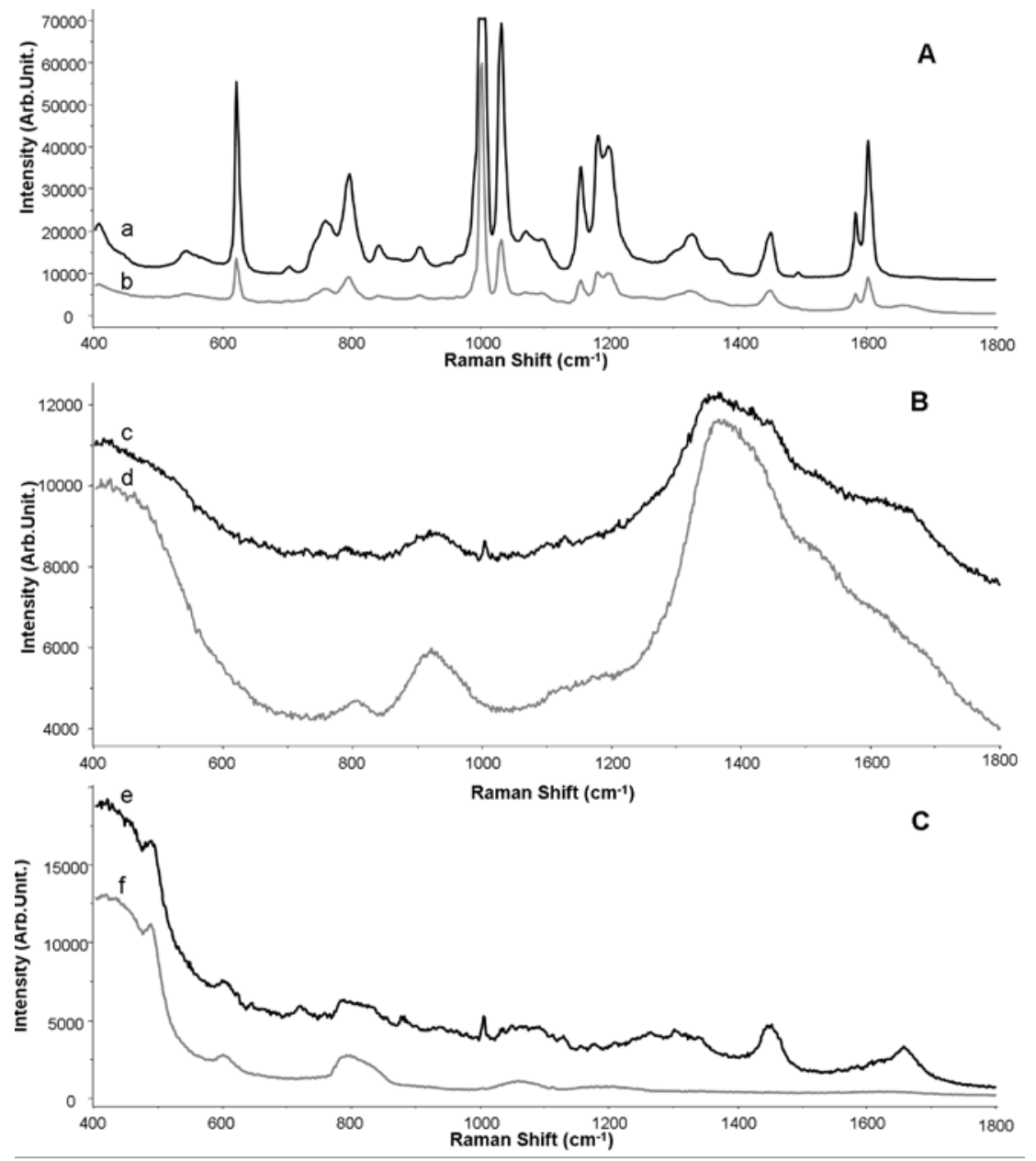

Figure 1: Comparison of the signal recorded on the plastic (A), glass (B) and quartz (C) substrates using a $785 \mathrm{~nm}$ laser source. The Raman spectra collected from cells grown on each substrates $(a, c$ and $e$ ) is compared to the pure signal obtained from the substrates ( $b, d$ and $f$ ). In the spectral range $400-1800 \mathrm{~cm}^{-1}$ the contribution of the substrates is overlapping with the cellular feature present in the spectra.

Furthermore, while the use of optically transparent substrates such as quartz or $\mathrm{CaF}_{2}$ windows can minimise the problem of the substrate contribution to the spectra recorded, the biocompatibility of these materials is rather poor, and the toxicity of the substrates can affect the cellular metabolism. Coating the substrates with a thin protein layer can improve the biocompatibility without compromising the spectral quality ${ }^{[13]}$, but it remains questionable whether a 2-D in vitro cell culture model is a relevant representation of an in vivo environment ${ }^{[14-16]}$. The interaction of the cells with their microenvironment can affect their proliferation ${ }^{[17]}$, metabolism or gene expression ${ }^{[18]}$ and how well they reproduce the cellular morphology and phenotype encountered in vivo [19].

This work aims to improve the protocols for the application of Raman spectroscopy to live cell analysis, significantly reducing the spectral background and thus the spectral preprocessing requirements. 3D collagen gels are proposed as a more suitable substrate 
for Raman spectroscopy, offering an improved environment for the cells, mimicking the extra-cellular matrix and therefore the in vivo conditions.

\section{MATERIALS AND METHODS}

\subsection{A549 and HaCaT Cell lines}

A549 cells from a human lung adenocarcinoma with the alveolar type II phenotype were obtained from ATTC (Manassas, VA, USA). Cells were cultured in RPMI 1640 (Gibco, Karlsruhe) supplemented with L-glutamine, penicillin and streptomycin (Gibco) and 10\% foetal calf serum (FCS, Biochrom, Berlin) in a humidified atmosphere containing 5\% $\mathrm{CO}_{2}$ at $37^{\circ} \mathrm{C}$.

\subsection{Collagen gels}

Solutions of collagen I from rat tail tendons (Gibco) were used for preparation of the collagen gels. The $5 \mathrm{mg} / \mathrm{mL}$ solution was mixed with sterile $10 \mathrm{X}$ phosphate buffered saline (PBS), sterile distilled water $\left(\mathrm{dH}_{2} \mathrm{O}\right)$ and $1 \mathrm{M} \mathrm{NaOH}$. The appropriate relative quantities of these components is determined by the final concentration $(3 \mathrm{mg} / \mathrm{mL})$ and volume needed. All the steps were carried out on ice to slow the gelation process. After mixing, the solution was placed in a Petri-dish for Raman spectroscopy before incubation at $37^{\circ} \mathrm{C}$ degrees in a $95 \%$ humidity incubator until a solid gel is formed (about 30mins).

\subsection{Sample preparation}

Cell samples: A549 cells were loaded at a concentration of $4 \times 10^{4}$ cells, onto collagen gels (prepared as described above) and $\mathrm{CaF}_{2}$ windows for comparison. To facilitate the manipulation of the samples, $30 \mathrm{~mm}$ Petri dishes (Stardest, USA) have been preferred for Raman spectroscopic measurements. All samples were incubated for $24 \mathrm{H}$ at $37^{\circ} \mathrm{C}, 5 \%$ $\mathrm{CO}_{2}$ before measurements.

\subsection{Observation of live cells}

In order to compare the cell morphology in 3-D gels versus 2-D environments, samples were imaged using a confocal microscope (LSM 510 META, Zeiss, Germany) equipped with a x40 objective.

\subsection{Raman spectroscopic measurements}

A Horiba Jobin-Yvon LabRAM HR800 spectrometer with an external $300 \mathrm{~mW}$, single mode, diode laser operating at $785 \mathrm{~nm}$ as source was used throughout this work. For all measurements, a x100 immersion objective (LUMPlanF1, Olympus, N.A. 1.00W) was employed. The confocal hole was set at $100 \mu \mathrm{m}$ for all measurements, the specified setting for confocal operation. The system was pre-calibrated to the $520.7 \mathrm{~cm}^{-1}$ spectral line of Silicon. The Labram system is a confocal spectrometer that contains two interchangeable gratings (300 and 900 lines/mm respectively). In the following 
experiments, the 300 lines/mm grating was used, which gave a spectral dispersion of around $1.5 \mathrm{~cm}^{-1}$ per pixel. The detector used was a 16-bit dynamic range Peltier cooled CCD detector. Images of the sample were acquired using a video camera within the system.

Lateral resolution testing: Iron oxide particles of $1 \mu$ m diameter, deposited on glass slides as described above, were selected for measurement. Linescans through the particles were conducted with a step size of $0.2 \mu \mathrm{m}$ in order to map out the convolution of the focal profile and particle size.

\section{RESULTS AND DISCUSSION}

The contribution of the substrates used in the spectra recorded can be limiting in the interpretation of the results. As discussed in the introduction, polystyrene based substrates and glass slides should be avoided for Raman spectroscopy. Although quartz is commonly used to grow the cells; it has been decided to opt for $\mathrm{CaF}_{2}$ windows for the realization of this work in order to reduce as much as possible the contribution of the substrate in the spectra recorded ${ }^{[20,21]}$.

\subsection{Live cells for Raman spectroscopy}

Chemical fixation of cells for imaging using techniques such as confocal fluorescence microscopy, infrared spectroscopy and even Raman spectroscopy allows the cells to be maintained in a well defined state for extended analysis. After alcohol fixation the cells can be kept at $4^{\circ} \mathrm{C}$ for prolonged periods before performing the analysis. As conventional microscopic techniques primarily monitor cell morphology, the fixation do not affect the observations made. However, Raman spectroscopy probes the molecular composition of the cells, and thus any treatment involving chemicals can significantly effect the signal collected. Figure 2 displays examples of spectra recorded from fixed cells deposited on $\mathrm{CaF}_{2}$. The cells have been kept in methanol for 10 mins before being air dried for $1 \mathrm{hr}$ at room temperature. The signal from the $\mathrm{CaF}_{2}$ corresponding to the background has been subtracted from the data before applying a baseline correction. Many specific peaks can be identified and assigned to cellular features in both the nucleolus spectrum (figure 2A) and cytoplasm (figure 2B). The literature is really rich is assignments and in this case the most interesting observation is the lack of differences between the 2 spectra. The main differences have been highlighted in grey for clarity. The cytoplasm and nucleolus have been targeted for illustration purpose as they are completely different compartments present in the cell with different function and composition. A similar set up has then been used to record live cells. The cells have been kept in $0.9 \% \mathrm{NaCl}$ during the recording of the spectra. The spectrum corresponding to the nucleolus is represented in figure 3A and is compared that of the cytoplasm (figure 3B). The spectra now exhibit strong differences and the spectrum from the nucleolus can easily be distinguished from the spectrum of the cytoplasm. The fixation process clearly has affected the molecular composition of the cells and resulting in a modification of the spectral signatures recorded for the different locations. To avoid any variations in the constitution of the cells, the study of live cells is thus desirable. As it is really difficult to estimate the impact of each fixative on the 
cellular content ${ }^{[7,20,21]}$, keeping the cells in their original state promises the collection of more accurate spatially specific information.

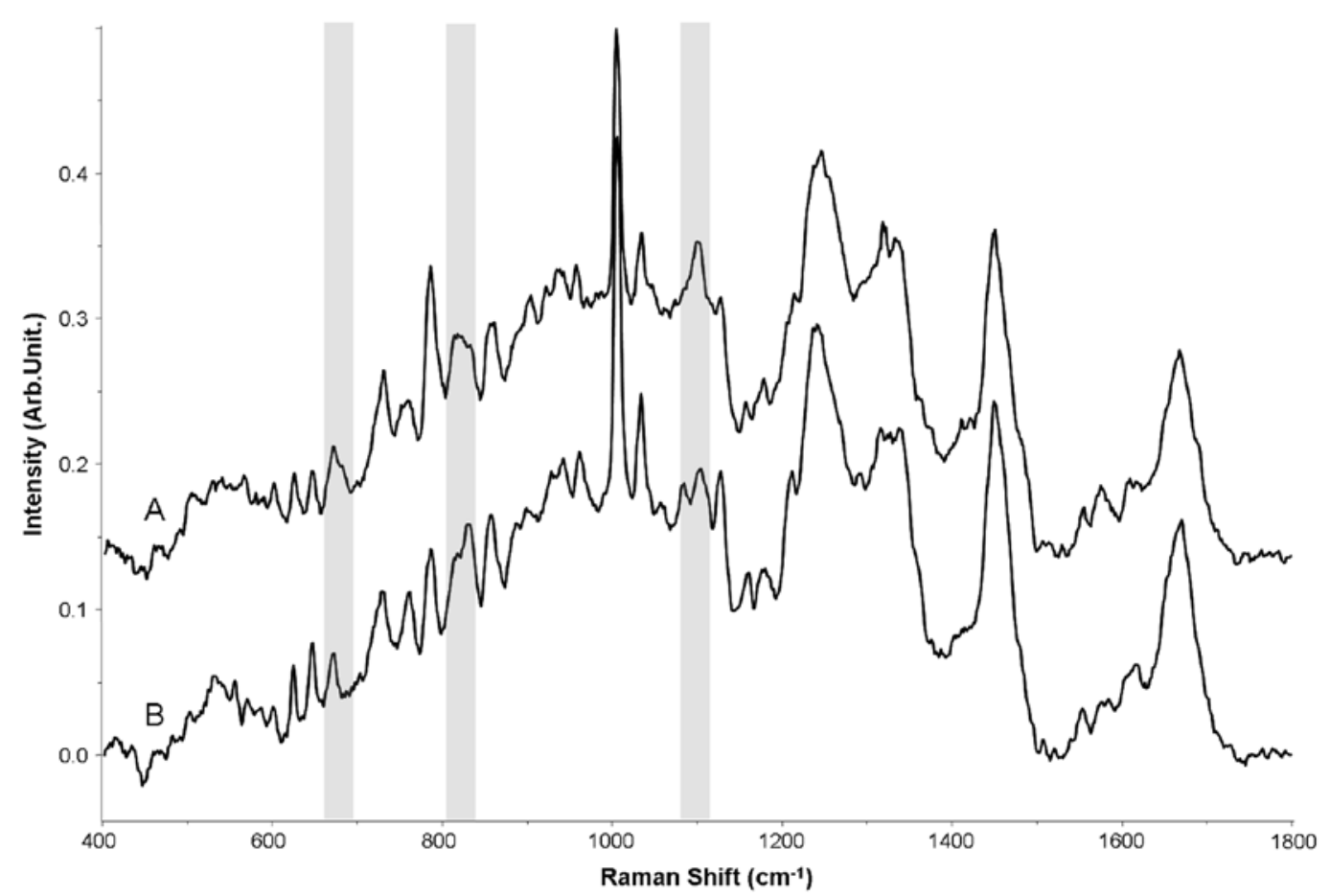

Figure 2: Comparison of the Raman spectra collected from A549 cells after dry fixation using methanol. The cells have been placed on $\mathrm{CaF}_{2}$ and spectra have been collected from the nucleus (A) and the cytoplasm (B). The principal variations existing in the spectral profiles have been highlighted in grey. 


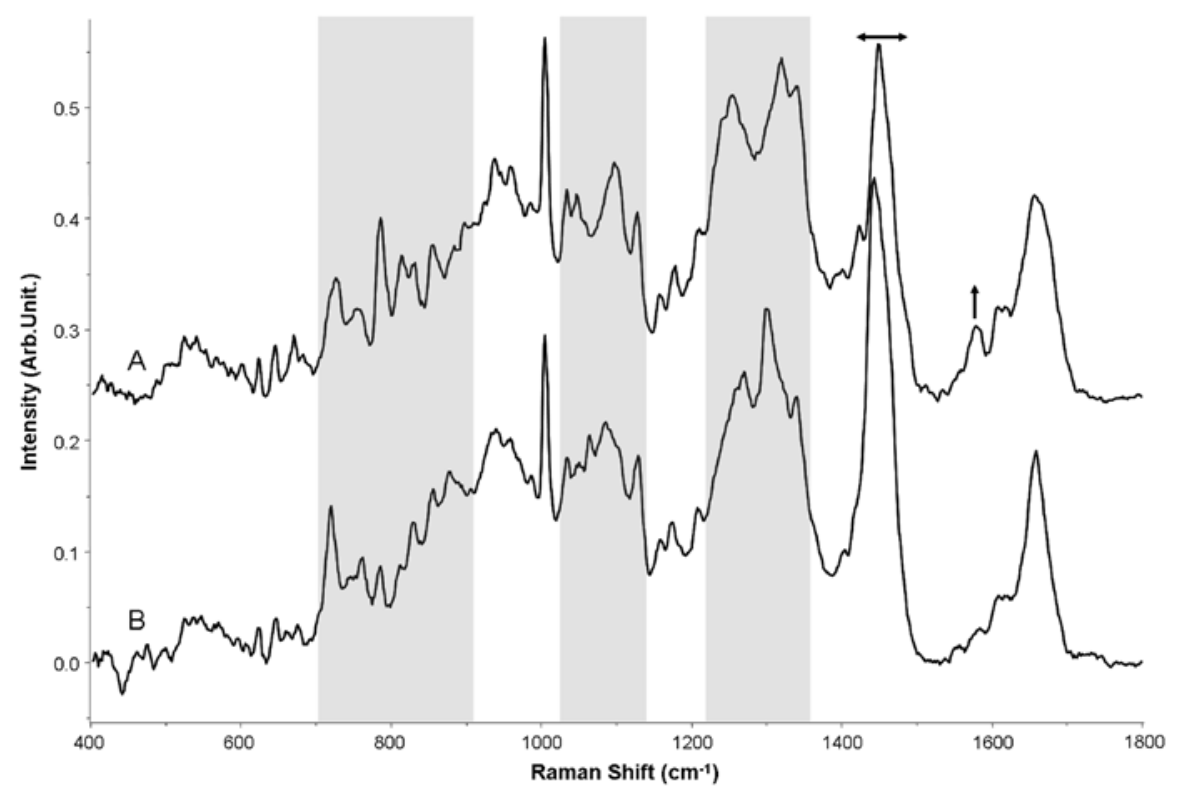

Figure 3: Comparison of the Raman spectra collected from live A549 cells. The cells have been placed on CaF $F_{2}$ and spectra have been collected from the nucleus (A) and the cytoplasm (B). The principal variations existing in the spectral profiles have been highlighted in grey.

\subsection{Limit of detection of Raman spectroscopy}

Raman spectroscopy is a highly sensitive technique giving specific information about the molecular composition of the samples under investigation. Although its potential for biological materials analysis has been proven many times, its limits of detection are rarely discussed. To illustrate this effect, different solutions have been tested. The spectrum presented in figure 4A corresponds to distilled water. Typically, no peaks can be observed in the spectral range $400-1800 \mathrm{~cm}^{-1}$ and only a broad band around $1650 \mathrm{~cm}^{-1}$ can be seen. The spectrum of figure 4B was recorded from the DMEM medium used for the cell culture and although it contains many inorganic salts, amino acids, vitamins and other molecules such as glucose or HEPES, the signature remains identical to the one collected from water. In this case, the different components diluted in the medium are present in concentrations too low to be detected by Raman spectroscopy. The spectrum of figure 4C has been obtained from a FBS (Foetal Bovine Serum) solution usually mixed with the medium to grow the cells. It is rich in different proteins and growth factors which are detected by Raman spectroscopy. Different peaks can be identified in the spectrum, especially in the spectral range $1000-1700 \mathrm{~cm}^{-1}$, indicating that the concentration is above the limit of detection of the technique. However, the FBS is usually diluted to $5-10 \%$ in the medium for cell culture and in this case none of the peaks present in the spectrum of the FBS can be seen (figure 4D). The notion of limit of detection is really important to understand what can influence the Raman spectra when working on live cells. In this case the absence of features of any of the different 
components present in the mixture used for cell culture indicates that Raman spectra can be collected from live cells kept in their growth medium, a consideration which is favorable for extended measurements.

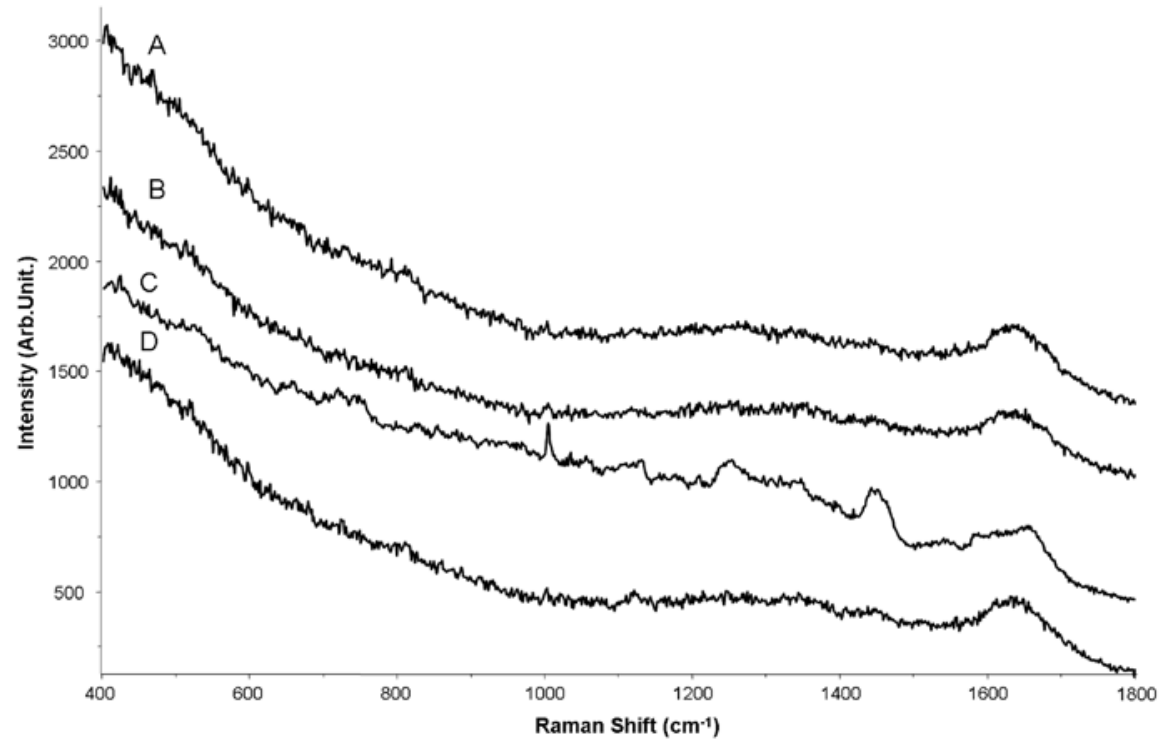

Figure 4: Comparison of the Raman spectra collected from distilled water (A), DMEM medium (B), FBS mixture (C) and Medium containing 10\% FBS (D).

\subsection{Collagen gels: A new substrate for Raman spectroscopy of live cells}

As described in the previous section, the limit of detection of the technique can make molecules essentially invisible to Raman spectroscopy. In addition to benefit of using full culture medium during the measurements, it opens new possibilities in the choice of substrates. Over the last few years, the interaction of cells with their microenvironment has become a concern for biologists. It has been highlighted many times in the literature how the use of different matrices can affect the cellular morphology, proliferation and metabolism ${ }^{[22-25]}$. It has also been demonstrated that the use of 3D matrices could protect the cells against the action of anticancer agents, or reduce the radiation induced toxicity [26, 27]. As the cell behavior is considerably affected by the interaction with the environment; the relevancy of observations made on 2D plastic substrates remains questionable. Due to their increased depth resolution, confocal microscopy and multiphoton microscopy can be easily applied to such 3D models ${ }^{[28]}$.

Although the potential of Raman spectroscopy has been clearly demonstrated for cellular analysis, it is important to keep the technique up to date with the different improvements made concerning microenvironment and matrices used for cellular investigation. The substrate Raman spectrum is the main contribution to the background present in spectra 
collected from live cells. The use of gels formed of collagen as a substrate might be similarly expected to contribute significantly, but, as was observed for the cell culture medium, the low density of the gel results in the contributions being below the limit of detection of the technique. Figure 5A shows the spectrum of the collagen mixture used to prepare the gels. The concentration is $\sim 5 \mathrm{mg} / \mathrm{mL}$ and no specific features from the collagen can be seen. The spectrum is identical to that of water (figure $5 \mathrm{~B}$ ). A spectrum recorded from the collagen gel at a concentration of $2.5 \mathrm{mg} / \mathrm{mL}$ will display the same profile (figure 5C). In these 2 cases, the concentration of collagen is too low to be detected by Raman spectroscopy, and thus the collagen gels appear to be invisible to the technique. To illustrate this phenomenon, a spectrum has been recorded after placing the collagen gel on a $\mathrm{CaF}_{2}$ window and drying at $37^{\circ} \mathrm{C}$ for a few hours. After deposition of the collagen fibers on the substrate it is possible to collect a Raman spectrum exhibiting spectral features belonging to the collagen but also the different salts used for the preparation of the gels (figure 5D).

Because the contribution of the collagen gels is reduced to the signal of water, it is possible to record Raman spectra from live cells grown on such substrates. The cells have a similar morphology (figure 6A) and the nucleus, nucleolus, and cytoplasm are clearly identifiable. Using a x100 immersion objective, distinct spectra can be collected for the different cellular compartments (figure 6B and 6C).

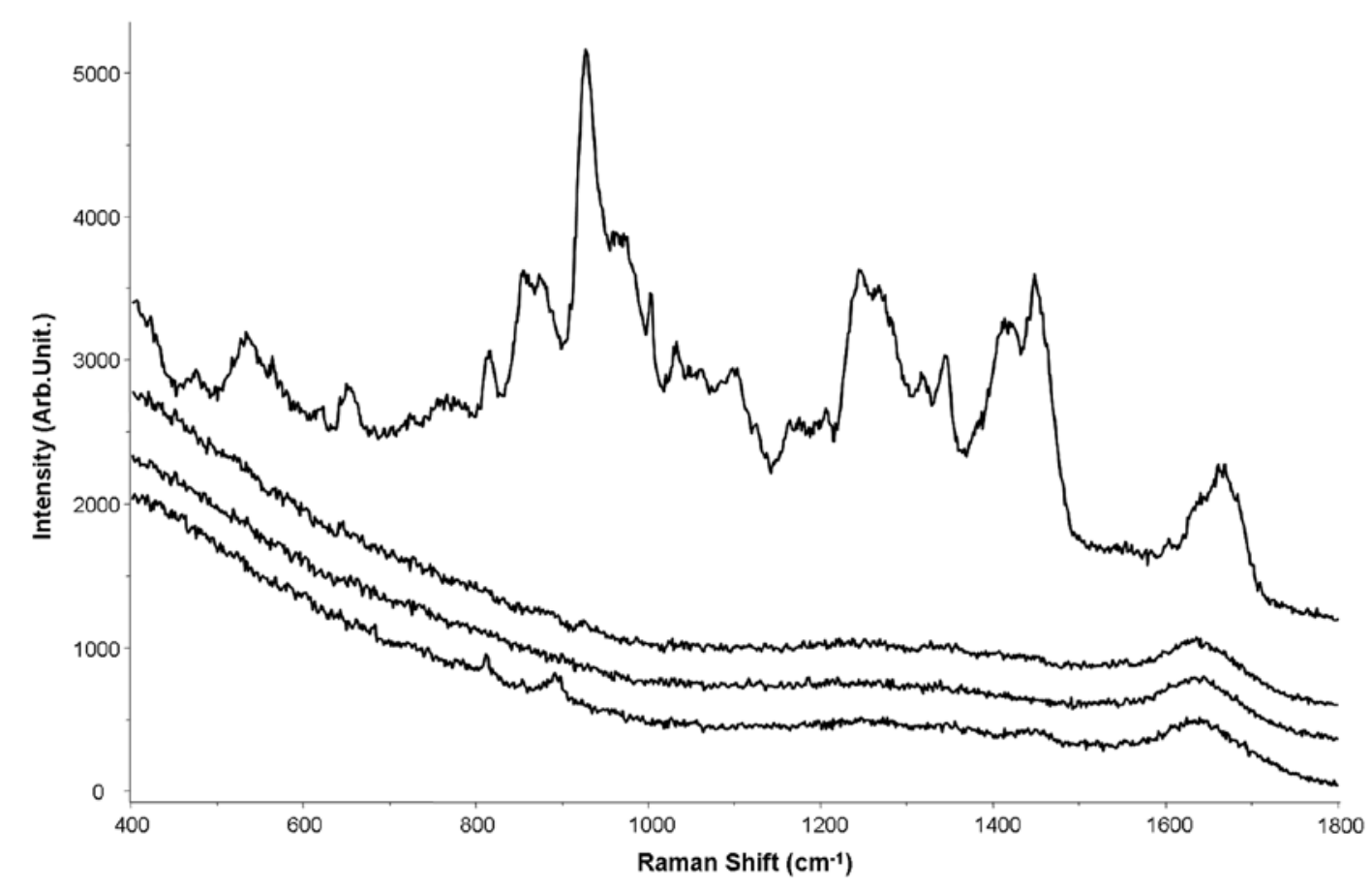


Figure 5: Comparison of the Raman spectra collected from the collagen mixture at a concentration $5 \mathrm{mg} / \mathrm{mL}(\mathrm{A})$, distilled water (B), collagen gels at a concentration of $2.5 \mathrm{mg} / \mathrm{mL}(\mathrm{C})$ and collagen gels at a concentration of 2.5 $\mathrm{mg} / \mathrm{mL}$ after drying (D).
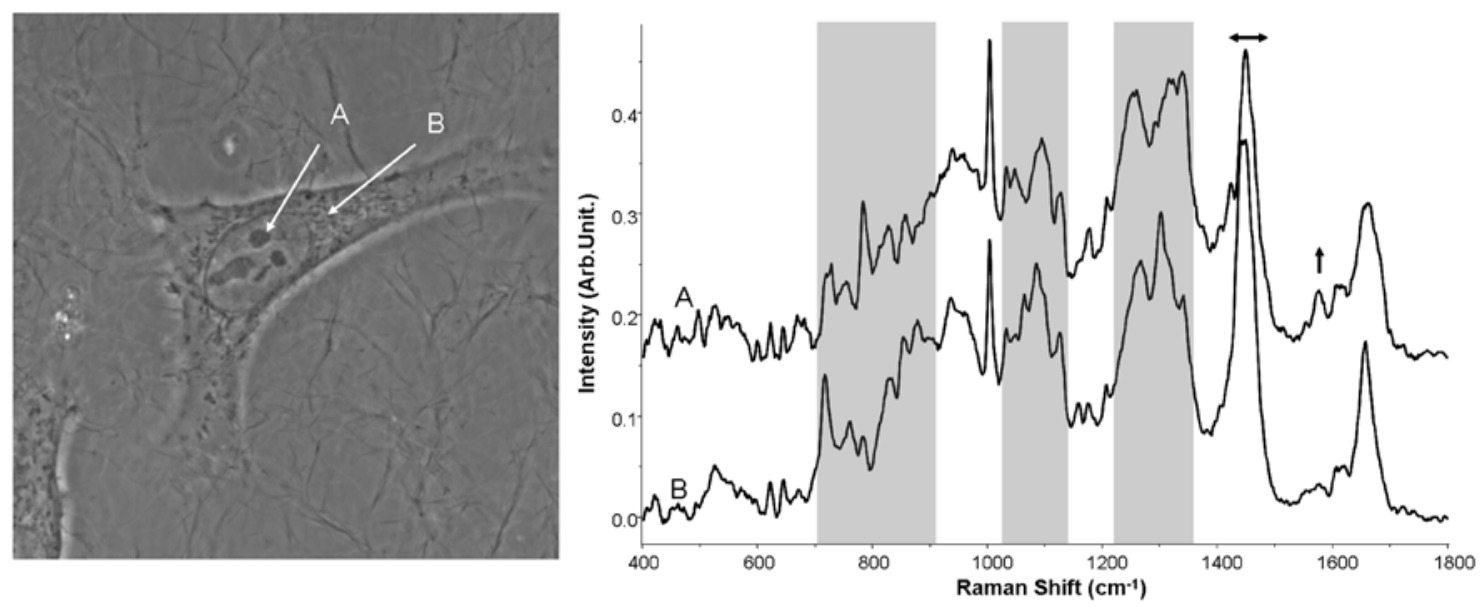

Figure 6: Example of Raman spectra collected from live cells grown on collagen gels substrates from the nucleus (A) and the cytoplasm (B). The corresponding locations can be visualized on the picture taken from an A549 cell grown on collagen gels.

\section{CONCLUSION}

What could appear as limitations for the detection of low concentration of molecules in solutions can also be perceived as advantageous for the study of live cells. In this work it has been demonstrated how the study of live cells can be improved by choice of environment. Firstly, the absence of signal from the different molecules present in the medium opens new perspectives for the application of Raman spectroscopy for prolonged measurements. Spectroscopic monitoring could be easily employed in parallel with live observer microscopes to bring complementary molecular information. Secondly, the invisibility of the collagen gels offers new applications for the study of cellular responses to different toxic agents in an appropriate environment, thereby enhancing the relevancy of the results collected. Finally, these improvements will contribute to reduce the gap existing between Raman spectroscopy and conventional microscopy techniques such as confocal microscopy and multiphoton microscopy proving its potential for live cells analysis. 


\section{ACKNOWLEDGEMENTS}

This research was supported by the National Biophotonics and Imaging Platform (NBIP) Ireland funded under the Higher Education Authority PRTLI (Programme for Research in Third Level Institutions) Cycle 4, co-funded by the Irish Government and the European Union. 


\section{REFERENCES}

[1] C. Matthaus, T. Chernenko, J. A. Newmark, C. M. Warner, M. Diem, Biophys J 93, 668. (2007)

[2] M. Miljkovic, T. Chernenko, M. J. Romeo, B. Bird, C. Matthaus, M. Diem, Analyst 135, 2002. (2010)

[3] I. Notingher, L. L. Hench, Expert Rev Med Devices 3, 215. (2006)

[4] R. J. Swain, M. M. Stevens, Biochem Soc Trans 35, 544. (2007)

[5] G. J. Puppels, W. Colier, J. H. F. Olminkhof, C. Otto, F. F. M. d. Mu, J. Greve, Journal of Raman Spectroscopy 22, 217. (1991)

[6] F. Draux, P. Jeannesson, A. Beljebbar, A. Tfayli, N. Fourre, M. Manfait, J. SuleSuso, G. D. Sockalingum, Analyst 134, 542. (2009)

[7] F. Draux, C. Gobinet, J. Sule-Suso, A. Trussardi, M. Manfait, P. Jeannesson, G. D. Sockalingum, Anal Bioanal Chem 397, 2727. (2010)

[8] A. D. Meade, C. Clarke, F. Draux, G. D. Sockalingum, M. Manfait, F. M. Lyng, H. J. Byrne, Anal Bioanal Chem 396, 1781. (2010)

[9] B. D. Beier, A. J. Berger, Analyst 134, 1198. (2009)

[10] C. A. Lieber, A. Mahadevan-Jansen, Appl Spectrosc 57, 1363. (2003)

[11] F. Bonnier, S. M. Ali, P. Knief, A. D. Meade, W. Hornebeck, H. Lambkin, K. Flynn, V. McDonagh, C. Healy, T. C. Lee, F. M. Lyng, H. J. Byrne, Journal of Raman spectroscopy DOI 10.1002/jrs.2825. (2010)

[12] F. Bonnier, A. D. Meade, S. Merzha, P. Knief, K. Bhattacharya, F. M. Lyng, H. J. Byrne, Analyst 135, 1697. (2010)

[13] A. D. Meade, F. M. Lyng, P. Knief, H. J. Byrne, Anal Bioanal Chem 387, 1717. (2007)

[14] J. L. Horning, S. K. Sahoo, S. Vijayaraghavalu, S. Dimitrijevic, J. K. Vasir, T. K. Jain, A. K. Panda, V. Labhasetwar, Mol Pharm 5, 849. (2008)

[15] J. B. Kim, Semin Cancer Biol 15, 365. (2005)

[16] K. S. Smalley, M. Lioni, M. Herlyn, In Vitro Cell Dev Biol Anim 42, 242. (2006)

[17] A. J. Garcia, M. D. Vega, D. Boettiger, Mol Biol Cell 10, 785. (1999)

[18] L. T. Allen, M. Tosetto, I. S. Miller, D. P. O'Connor, S. C. Penney, I. Lynch, A. K. Keenan, S. R. Pennington, K. A. Dawson, W. M. Gallagher, Biomaterials 27, 3096. (2006)

[19] K. E. Sung, G. Su, C. Pehlke, S. M. Trier, K. W. Eliceiri, P. J. Keely, A. Friedl, D. J. Beebe, Biomaterials, doi:10.1016/j.biomaterials.2009.05.043. (2009)

[20] M. M. Mariani, P. Lampen, J. Popp, B. R. Wood, V. Deckert, Analyst 134, 1154. (2009)

[21] A. D. Meade, C. Clarke, F. Draux, G. D. Sockalingum, M. Manfait, F. M. Lyng, H. J. Byrne, Anal Bioanal Chem. (2010)

[22] N. Cordes, V. Meineke, Strahlenther Onkol 179, 337. (2003)

[23] N. Cordes, D. van Beuningen, Br J Cancer 88, 1470. (2003)

[24] N. Fourre, E. Millerot-Serrurot, R. Garnotel, J. M. Zahm, N. Bonnet, J. M. Millot, P. Jeannesson, Cancer Sci 99, 1699. (2008)

[25] S. Ishihara, H. Haga, M. Yasuda, T. Mizutani, K. Kawabata, H. Shirato, T. Nishioka, Biochem Biophys Res Commun 396, 651. (2010)

[26] R. Harisi, J. Dudas, J. Nagy-Olah, F. Timar, M. Szendroi, A. Jeney, Cancer Biol Ther 6, 1240. (2007) 
[27] M. B. Sowa, W. B. Chrisler, K. D. Zens, E. J. Ashjian, L. K. Opresko, Mutat Res 687, 78. (2010)

[28] B. W. Graf, S. A. Boppart, Methods Mol Biol 591, 211. 